\title{
Erratum
}

\section{Surgical Endoscopy}

Surg Endosc (1996) 10: 701-702

For your reference, below is the complete Table of Contents for the 1995 SAGES Postgraduate Course which appeared in Surgical Endoscopy, Volume 9, Numbers 11 and 12.

1995 SAGES Postgraduate Course. I

L.W. Traverso, Course Director

1211 Surgical endoscopy-outcomes and costs

K.A. Forde

1211 Introduction

L.W. Traverso

1213 Outcomes in medical care-what are they?

B.V. MacFadyen

1214 Prospective randomized trials in clinical research

B.M. Wolfe, K.A. Mathieseu

1216 Utilization analysis and physician profiling-new paradigm, old paradigm

P. Caper

1220 Moderator's overview

C.K. McSherry

1221 Cost-effectiveness of laparoscopic and mini-cholecystectomy in a prospective randomized trial

J.S. Barkun, J.J. Caro, A.N. Barkun, E. Trindade

1224 Laparoscopic cholecystectomy: the Maryland experience

H.A. Pitt

1225 Laparoscopic cholecystectomy: the Mississippi experience

C.R. Voyles

1230 Laparoscopic cholecystectomy in Australia-outcomes

and costs

D.R. Fletcher

1235 ERCP after laparoscopic cholecystectomy

R.A. Kozarek

1240 Laparoscopic transcystic duct common bile duct exploration-outcome and costs

E.H. Phillips

1242 CBD stones-outcomes and costs: lararoscopic transcystic techniques other than choledochoscopy

L.W. Traverso, T.S. Roush, K. Koo

1244 Static cholangiography vs digital fluoroscopy-

intraoperative cholangiography: benefit and cost ratio

G. Berci 
1995 SAGES Postgraduate Course. II

L.W. Traverso, Course Director

1306 Surgical endoscopy-outcomes and costs

K.A. Forde

1306 Moderator's overview

L.M. Nyhus

1307 Laparoscopic vs inguinal hernia repairs: outcomes and costs L.S. Schultz

1311 Open vs laparoscopic hernea repair: analysis of costs, charges, and outcomes

J.W. Schurz, M.E. Arregui, J.C. Hammond

1317 Moderator's overview

J.A. Coller

1318 Laparoscopic colon resection for cancer D.M. Ota

1322 Laparoscopic vs open colon surgery: costs and outcome J. Pfeifer, S.D. Wexner, P. Reissman, M. Bernstein, J.J. Nogueras, S. Singh, E. Weiss

1326 Examination of outcome and cost data of open and laparoscopic antireflux operations at Virginia Mason Medical Center in Seattle

D.E. Low

1328 Results of Nissen fundoplication: a cost analysis R.A. Hinder, F. Raiser, N. Katada. P.J. McBride, G. Perdikis, R.J. Lund

1332 Postoperative conplications of anti-reflux surgery: outcomes and costs

R.A. Kozarek 